\title{
DE
} DE GRUYTER OPEN

\section{THE IMPACT OF EXCHANGE RATES AND INTEREST RATES ON BANK STOCK RETURNS: EVIDENCE FROM U.S. BANKS}

\author{
PRITI Verma \\ College of Business Administration \\ Texas A\&M University, Kingsville, India
}

\begin{abstract}
:
This paper examines the mean, volatility spillovers and response asymmetries between short-term and long-term interest rates, exchange rates and portfolios of money center, large and medium-sized banks in the U.S. I use the multivariate version of Nelson's (1991) Exponential Generalized Autoregressive Conditionally Heteroscedastic (EGARCH) model. Results indicate mean and volatility spillovers from short-term interest rates and exchange rates and long-term interest rates and exchange rates to three bank portfolios. Results also show response asymmetries from short-term interest rates and exchange rates and long-term interest rates and exchange rates to all the three bank portfolios. These findings have important implications for bankers in terms of devising different hedging strategies against interest rates and exchange rate risks.
\end{abstract}

Key words: Bank stock returns, EGARCH, Interest rates, Exchange rates

\section{Introduction}

The 1970s and 1980s experienced numerous bank failures. This was mainly due to high interest rates and interest rate sensitivity. Further, banks have moved away from commercial loans to securities at a fast pace. Another major concern amongst investors, banking authorities, academicians and policy makers are the volatility of the financial markets and its impact on interest rate changes of bank stocks. This in turn has led to several researches examining the effect of interest rate on bank stock returns using a two-index market model assuming of constant variance (Stone 1974, Lloyd and Shick 1977, Chance and Lane 1980, Lynge and Zumwalt 1980, Flannery and James 1984, Booth and Officer 1985, Scott and Peterson 1986, and Bae 1990); a few studies examining interest rate sensitivity of bank stock returns under time-varying 
conditions (Kane and Unal 1988, Kwan 1991, Choi et al., 1992, and Wetmore and Brick 1994). Some other studies by show that bank stock returns are more sensitive to changes in long-term interest rates than to changes in short-term interest rates (Akella and Chen, 1990 and Mansur and Elyasiani, 1995). Further, a few studies use ARCH / GARCH type methodology to examine the relationship between interest rate and bank stock returns (Song 1994, Neuberger 1993, Elyasiani and Mansur 1998, Tai 2000, Elyasiani and Mansur 2004, Verma and Jackson, 2008).

Furthermore, exchange rate volatility has increased after the flexible exchange rate regime in the 1970s and the increasing globalization of the economy. These fluctuations in exchange rate affect the profits and losses of banks depending on the bank's net foreign positions. Most of the empirical work focuses primarily on the relationship between interest rates and bank stock returns. A very few studies examine the joint interaction between exchange rates and interest rates on bank stocks returns (Choi et. al.,1992, Wetmore and Brick 1994, 1998, Tai, 2000 and Kasman et. al., 2011). This is important to include exchange rate as exchange rate risk could be another potential determinant of bank stock returns.

The purpose of this paper is to jointly examine how interest rates and exchange rates affect bank stocks. This paper extends current literature regarding interest rate and exchange rate sensitivity by using the multivariate extension of Nelson's (1991) Exponential Generalized Autoregressive Conditionally Heteroscedastic (EGARCH) model to investigate the linkages that exist between interest rates, exchange rates and bank stock returns. Another area that has been overlooked in the literature is the response asymmetries of interest rates and exchange rates on bank stock returns. This study builds on the studies of Elyasiani and Mansur (2004), and Verma and Jackson (2008) in analyzing mean, volatility spillovers, and response asymmetries from interest rates and exchange rates to bank stock returns. Since current literature documents that negative innovations have bigger impacts on volatility than positive innovations (Cheung and Ng, 1992; Koutmos, 1992; Bae and Karolyi, 1994; Koutmos and Booth, 1995), there is a possibility that such an effect will hold for bank stocks. By investigating and comparing the effect of negative and positive innovations simultaneously, this paper provides additional insights of how information is transmitted from interest rates and exchange rates to bank stocks.

The impact of interest rate and exchange rate changes on bank stock returns is an indicator on the bank's exposure to risk. A priori, these results are expected to be different for Money Center (MC), Large (LG) and medium-sized (MED) banks. One possible reason could be the type of activities these banks are involved in. MC and LG banks are more into fee based activites whereas MED banks have large investments in long-term bonds and unhedged mortgages.

We contribute to current literature in three distinct ways: First, the use of multivariate EGARCH allows us to estimate bank stock returns, interest rate and exchange rate volatility within the same system of equations and in a one-step procedure. This gives a more comprehensive picture of the relationships of interest rates and exchange rates on bank stock returns, as these relationships are not 
necessarily linear. Second, this framework allows us to examine the impact of interest rate and exchange rate changes on mean and conditional variance of bank stock returns. This accounts for the time-varying nature of risk premiums, which enables us to explore the linear and nonlinear relationships of interest rates and exchange rates on bank returns. Third, the EGARCH framework facilitates the investigation of the asymmetric impact of positive and negative interest rate and exchange rate changes on bank stock return volatility.

Results indicate mean and volatility spillovers from short-term interest rates and exchange rates, and long-term interest rates and exchange rates to MC, LG and MED banks. In terms of mean and volatility spillovers from short-term interest rates and exchange rates. MC banks spillovers to MED banks, LG banks spillover to MED and MED banks spillover to LG banks. Additionally, there is a feedback effect from MC to MED and from LG to MED banks. For long-term interest rates and exchange rates, MC banks spillover to MED and LG, LG banks spillover to MED and MC banks and the MED banks spillover to the LG and MC banks. There are also feedback effects seen from MC to LG and MED banks, LG to MC and MED banks and from MED to MC and LG banks.

Results also show response asymmetries from short-term interest rates and exchange rates, and long-term interest rates and exchange rates to all the three bank portfolios. These results show that MC, LG and MED banks are more sensitive to bad news than good news as a result of changes in short-term interest rates and exchange rates and long-term interest rates and exchange rates.

The remainder of the paper is organized as follows: Section 2 discusses the empirical framework while Section 3 highlights the data and Section 4 the econometric methodology. Section 5 discusses the empirical results, followed by the concluding remarks in Section 6.

\section{Empirical Framework}

Spillovers are the information links across markets, i.e. how new information revealed in one market affects another market. Volatility spillover is a short-term mechanism by which volatility in one market affects the volatility in another market (So, 2003). A good understanding of the origin and intensity of spillovers is therefore essential for many financial decisions, global hedging strategies, and for securities pricing ( $\mathrm{Ng}, 2000)$. In addition, bank regulators need to understand the nature of spillovers in order to appropriately assess capital adequacy and the impact of proposed policy changes.

Interest Rate and Bank Stocks:

The effect of interest rates on bank stock returns was initially studied by Stone (1974), Lloyd and Shick (1977), Chance and Lane (1980), Lynge and Zumwalt (1980), Flannery and James (1984), Booth and Officer (1985), Scott and Peterson (1986), and Bae (1990) using a two-index model (interest rate and market factors) and under the assumption of constant variance. The findings of these studies were contradicting both 
in terms of direction and magnitude. One possible reason for these contrasting results may be the different treatments of interest rate changes (Bae 1990).

Several studies provide evidence against constant variance and argue that the effect of interest rate changes on bank stock returns is time-varying (Saunders and Yourougou, 1990; Yourougou, 1990; Kwan, 1991). Song (1994) was the first to demonstrate that $\mathrm{ARCH}$ type methodologies are suitable for bank stock analysis. The results of his work demonstrate that market and interest rate risk of banks vary significantly over time. Elyasiani and Mansur (1998) use a GARCH-M model to investigate the effect of interest rate and its volatility on bank stock returns. They find that interest rates impact the mean and variance of bank stock returns. Later, Elyasiani and Mansur (2004) employ a multivariate GARCH model to examine the bank stock return sensitivities to short term and long-term interest rates and provide evidence that both the rates and their volatilities impact the return generating process.

Verma and Jackson (2008) use the EGARCH model to examine the spillover effects and response asymmetries between short-term and long-term interest rates and the portfolios of money center, large and medium-sized banks in the U.S. Their results show that price, volatility spillovers and response asymmetries from both interest rates to the bank stock returns.

Exchange Rate, Interest Rate and Bank Stocks:

Choi et al., (1992) build on prior studies by including the impact of exchange rates along with interest rates. They find that interest rate and exchange rate sensitivity vary in both relatively stable and volatile interest rate periods. Wetmore and Brick (1994) use the model by Choi et al., (1992) and find that the coefficients of market risk, interest rate risk, and foreign exchange risk vary with time. Tai (2000) investigates the role of market, interest rates, and exchange rates in pricing bank stock returns by using three different econometric methodologies. Elyasiani and Mansur (2003) use bivariate GARCH to examine the sensitivities of bank stocks to the market, interest rate and exchange rate.

Kasman et.al. (2011) examine the impact on interest rates and exchange rates on bank stocks from Turkey. They find that interest rates and exchange rates have a negative and significant effect on the bank stocks.

This paper builds on the Verma and Jackson (2008) paper and uses EGARCH approach to jointly examine the impact of interest rate and exchange rates on bank stock returns. First, we determine the mean and volatility spillovers between short-term interest rates and exchange rates on portfolios of bank stock returns of MC, LG, and MED banks in the U.S. Second, we determine the mean and volatility spillovers between long-term interest rates and exchange rates on portfolios of bank stock returns of MC, LG, and MED banks in the U.S. It is important to estimate interest rates, exchange rates and bank stock returns together within the same system of equations because a change in either of these has an influence on the other. Third, we investigate if interest rate and exchange rate shocks have an asymmetric impact on bank stock returns. 
There is a large body of literature relating to interest rate and exchange rate impact on bank stocks. However, a void still exists relating the effect of both positive and negative changes in short- term interest rates and exchange rates on bank stock returns and the effect of both positive and negative changes in long- term interest rates and exchange rates on bank stock returns. This paper fills in the gap in the literature by examining response asymmetries of short-term interest rates and exchange rates as well as long-term interest rates and exchange rates (i.e. both positive and negative changes) concurrently for a sample of bank stocks.

\section{DATA}

The sample consists of 70 commercial bank stocks traded on the New York Stock Exchange or American Stock Exchange. This paper uses daily data from January 2, 1997 to December 31, 2002, a total of 1,508 observations. Data for the bank stock returns are taken from the CRSP database. Based on total assets at the end of 2002, I sort the banks by size into three portfolios - money center banks (MC), large banks (LG) and medium-size banks (MED). Banks with total assets less than $\$ 20$ billion constitute the MED sample; banks with total assets between $\$ 20$ billion and $\$ 90$ billion make up the LG sample and those banks with total assets greater than $\$ 90$ billion are classified as MC banks. The final sample has nine MC banks, twelve LG banks, and forty-nine banks making up the portfolio of MED banks. I construct valueweighted portfolios using the mean abnormal returns.

Table 1 - Descriptive Statistics of Bank Stock Returns

\begin{tabular}{|c|c|c|c|}
\hline Statistics & MED & LG & MC \\
\hline \multicolumn{4}{|c|}{ Panel A: Descriptive statistics of returns } \\
\hline Mean & 0.0010 & -0.0013 & -0.0013 \\
\hline Std. Dev. & 0.0121 & 0.0179 & 0.0201 \\
\hline Skewness & 0.5297 & 0.2449 & 0.2062 \\
\hline Kurtosis & 7.4529 & 4.9017 & 4.3198 \\
\hline Maximum & 0.0986 & 0.0902 & 0.0842 \\
\hline Minimum & -0.0417 & -0.0706 & -0.0830 \\
\hline Jarque-Bera & $1316.37^{* \star \star \star}$ & $242.30^{\star * \star}$ & $120.13^{\star * *}$ \\
\hline$L B(12)$ for $R_{1, t}$ & $25.42^{\star \star}$ & 14.51 & 7.31 \\
\hline $\mathrm{LB}(12)$ for $\mathrm{R}^{2}, \mathrm{t}$ & $346.87^{\star \star \star \star}$ & $534.97^{\star \star \star}$ & $311.02^{\star \star \star \star}$ \\
\hline \multicolumn{4}{|c|}{ Panel B: Correlation Coefficients } \\
\hline & MED & LG & $\mathrm{MC}$ \\
\hline MED & 1.0000 & 0.7950 & 0.8559 \\
\hline LG & & 1.0000 & 0.8900 \\
\hline $\mathrm{MC}$ & & & 1.0000 \\
\hline \multicolumn{4}{|c|}{$\begin{array}{l}\text { This table displays the descriptive statistics of portfolio returns. Medium-size banks } \\
\text { (MED) are defined as having total assets less than } \$ 20 \text { billion; Large banks (LG) are } \\
\text { defined as having total assets between } \$ 20 \text { billion and } \$ 90 \text { billion and Money-Center } \\
\text { banks (MC) are money-center banks defined as having total assets greater than } \$ 90 \\
\text { billion. LB(12) for } \mathrm{R}_{l, t} \text { is the Ljung-Box statistic which tests the presence of } \\
\text { autocorrelation, while } \mathrm{LB}(12) \text { for } \mathrm{R}^{2}, \mathrm{r} \text { is the statistic which tests the presence of } \\
\text { heteroscedasticity. The Jarque-Bera statistic tests the null hypothesis of normality. } \\
\text { Lastly, } * \approx *, * * \text { and * denote statistical significance at the } 1 \%, 5 \% \text { and } 10 \% \text { levels } \\
\text { respectively. }\end{array}$} \\
\hline
\end{tabular}


For short-term interest rate (STI), I use the 3- month T-bill yield and for the long-term interest rate (LTI) I use the 10-year Treasury Composite yield. Both shortand long-term interest rates are expressed as percentage change over the previous period. Data for interest rate has been taken from DataStream International. For exchange rates, I use the trade-weighted exchange rate of the U.S. dollar against a broad index of widely circulated currencies. This data is taken from the Federal Reserve Bank of St. Louis. The daily data series is appropriate for this study as it is argued that weekly returns may be too long to examine the fast impact from the interest rates to bank stock returns (Eun and Shim 1989, and Choudhry 1994).

Table 1 provides the descriptive statistics for our sample. The bank stock portfolio returns are positively skewed and leptokurtotic. The skewness statistics suggest lack of normality in the distribution of the returns of the portfolio series. The values of kurtosis indicate that the returns of each portfolio are more peaked than a normal distribution. The significant values of the Ljung-Box test statistics (LB) for the returns and the square of returns suggest the presence of autocorrelation and heteroscedasticity respectively in these series. Also, the Jarque-Bera normality test rejects the null hypothesis of normality. Clearly, these descriptive statistics indicate that these data fit the $\mathrm{ARCH}$ type modeling approach employed in this study. Panel $\mathrm{B}$ of Table 1 reports the correlations between the three bank portfolios and shows that all three bank portfolios are highly correlated with each other.

\section{Methodology}

Mean and volatility spillovers between short- and long-term interest rates, exchange rates and bank stock portfolios have been analyzed by using a multivariate extension of the EGARCH developed by Nelson (1991). Following Nelson (1991), researchers such as Koutmos (1996) and Koutmos and Booth (1995) used the multivariate EGARCH methodology to test their hypotheses. This analysis of the volatility linkages from interest rates and exchange rates to bank portfolios is investigated in a one-step estimation procedure, therefore eliminating the need to use estimated regressors.

The mean and volatility spillovers between the portfolios of MED, LG and MC banks are analyzed using the following vector autoregressive model (VAR):

$R_{i, t}=\beta_{i, 0}+\sum_{j=1}^{3} \beta_{i, j} R_{j, t-1}+\beta_{i, 4} R_{I N T, t-1}+\beta_{i, 5} R_{X R, t-1}+\varepsilon_{i, t} \quad$ for $i, j=1,2,3$

In this model, $\beta_{i, 0}, \beta_{i, j}, \beta_{i, 4}$ and $\beta_{i, 5}$ are parameters to be estimated and $\varepsilon_{i, j}$ represent changes with mean zero and variance $\sigma_{i, j}^{2}$. By construction, the positive and negative shocks of portfolio $i$ become part of the information set in portfolio $j(i, j=1,2,3$ where 1 = medium, $2=$ large, and 3 = money center $)$. 
Accordingly, $\beta_{i, j}$ (for $i=j$ ) implies that the portfolios are dependent on their past values, $\beta_{i, j}$ (for $i \neq j$ ) reflect the extent of mean spillovers across the three portfolios, $\beta_{i, 4}$ the effect of short- or long-term interest rates on our portfolios and $\beta_{i, 5}$ is the effect of exchange rates on our bank portfolios. $R_{i, t}$ is the daily return for bank $i$ at time $t-1, R_{j, t-1}$ is the daily return for bank $j$ at time $t, R_{I N T, t}$ is the interest rate at time $t-1$, $R_{X R, t}$ is the exchange rate at time $t-1$, and $z_{j, t-1}$ is the standardized change at time $t$ 1. The optimal lag length for the VAR model is one-period lag or VAR (1) after considering the parsimony principle and the residual's white-noise property.

The conditional variance between the bank portfolios is captured by using the multivariate version of Nelson's (1991) EGARCH specification given by Koutmos and Booth (1995):

$$
\begin{aligned}
& \sigma_{i, t}^{2}=\exp \left[\alpha_{i, 0}+\sum_{j=1}^{3} \alpha_{i, j} f_{j}\left(Z_{j, t-1}\right)+\gamma_{i} \ln \left(\sigma_{i, t-1}^{2}\right)+\alpha_{i, 4} R_{I N T, t-1}+\alpha_{i, 5} R_{X R, t-1}\right]_{\text {for } i=1,2,3} \\
& f_{j}\left(Z_{j, t-1}\right)=\left(\left|Z_{j, t-1}\right|-E\left(\left|Z_{j, t-1}\right|\right)+\delta_{j} Z_{j, t-1} \quad \text { for } j=1,2,3\right.
\end{aligned}
$$

where $Z_{j, t-1}$ is the standardized residual at time $t-1$, which is defined as $\varepsilon_{j, t-1} / \sigma_{j, t-1}$, and $E\left(\left|z_{j, t-1}\right|\right)$ is the expected absolute value of $z_{j, t-1}$. This conditional variance process allows its own lagged and cross-portfolio standardized shocks to exert an asymmetric impact on the volatility of portfolio $i$. The parameter $\alpha_{i, j}$ (for $i=j$ ) implies that the volatilities in each portfolio are dependent on their past values, $\alpha_{i, j}$ (for $i \neq j$ ) captures the volatility spillover between portfolios while the parameter $\alpha_{i, 4}$ captures the impact of short- or long-term interest rate volatilities on the portfolios and $\alpha_{i, 5}$ captures the volatility spillover from exchange rates on the portfolios. $R_{I N T, t}$ is the interest rate at time $t-1, R_{X R, t}$ is the exchange rate at time $t-1$, and $Z_{j, t-1}$ is the standardized change at time $t-1$. The parameter $\gamma_{i}$ measures the persistence in volatility and the unconditional variance is finite if $\gamma_{i}<1$. Asymmetry is modeled by equation (3) and the parameter $\delta_{j}$ measures the asymmetric impact of volatility of portfolios $i$. Asymmetry exists if $\delta_{j}$ is negative and statistically significant. Lastly, the difference $\left|z_{j, t-1}\right|-E\left(\left|z_{j, t-1}\right|\right)$ measures the size effect of a shock whereas $\delta_{j} z_{j, t-1}$ measures the corresponding sign effect. 
The log-likelihood for the multivariate EGARCH model is:

$$
L(\theta)=-(1 / 2)(N T) \ln (2 \pi)-(1 / 2) \sum_{t=1}^{T}\left(\ln \left|H_{t}\right|+\varepsilon_{t}^{\prime} H_{t}^{-1} \varepsilon_{t}\right),
$$

where $N$ is the number of equations (three), $T$ is the number of observations, $\theta$ is the vector of parameters to be estimated, $\varepsilon_{t}^{\prime}=\left[\varepsilon_{1, t} \varepsilon_{2, t} \varepsilon_{3, t}\right]$ is the $1 \times 3$ vector of interestrate changes at time $t, \theta$ is the $3 \times 3$ time varying conditional variance-covariance matrix with diagonal elements given by equation (2) for $i=1,2,3$ and cross-diagonal elements given by $\sigma_{i, j, t}=\rho_{i, j} \sigma_{i, t} \sigma_{j, t}$ for $i, j=1,2,3$ and $i \neq j$. Since this log-likelihood function is highly nonlinear in $\theta$ we use the $\mathrm{BHHH}$ (1974) algorithm for its optimization.

\section{Results}

The maximum likelihood estimates of the multivariate EGARCH model for short-term interest rates and exchange rates are shown in Table 2 and for the longterm interest rates and exchange rates are shown in Table 3 . The results show substantial evidence of multidirectional lead-lag relationships from interest rates and exchange rates to the three bank portfolios. The results also show response asymmetries for all the three bank portfolios.

\section{Short-Term Interest Rates and Exchange Rates}

Table 2 displays the mean and volatility spillovers from short-term interest rates and exchange rates to the MC, LG and MED portfolios. Results indicate mean spillovers from short-term interest rates to LG and MED banks. This implies that the banks are sensitive to changes in short-term interest rates. This is due to their interestrate exposure. Our results further suggest mean spillovers from exchange rates to $\mathrm{MC}$, and MED banks. This indicates that exchange rate movements play an important role in pricing of bank stocks. Sensitivity of bank stocks to changes in interest rate and exchange rate is an indicator of interest rate and exchange rate exposure of banks. Consequently these results have important implications for bank managers, regulatory authorities and investors in the banking sector.

In terms of mean spillovers between bank portfolios, MC banks spillover to MED banks, LG banks spillover to MC and MED banks and the MED banks spillover to $M C$ and LG banks. In addition, there is a feedback effect from the MC to MED banks and from LG to the MED banks. It is important for bankers to understand the feedback effect as bankers will then be able to limit their interest rate exposure and positions taken in the derivatives market (Elyasiani and Mansur, 2004). 


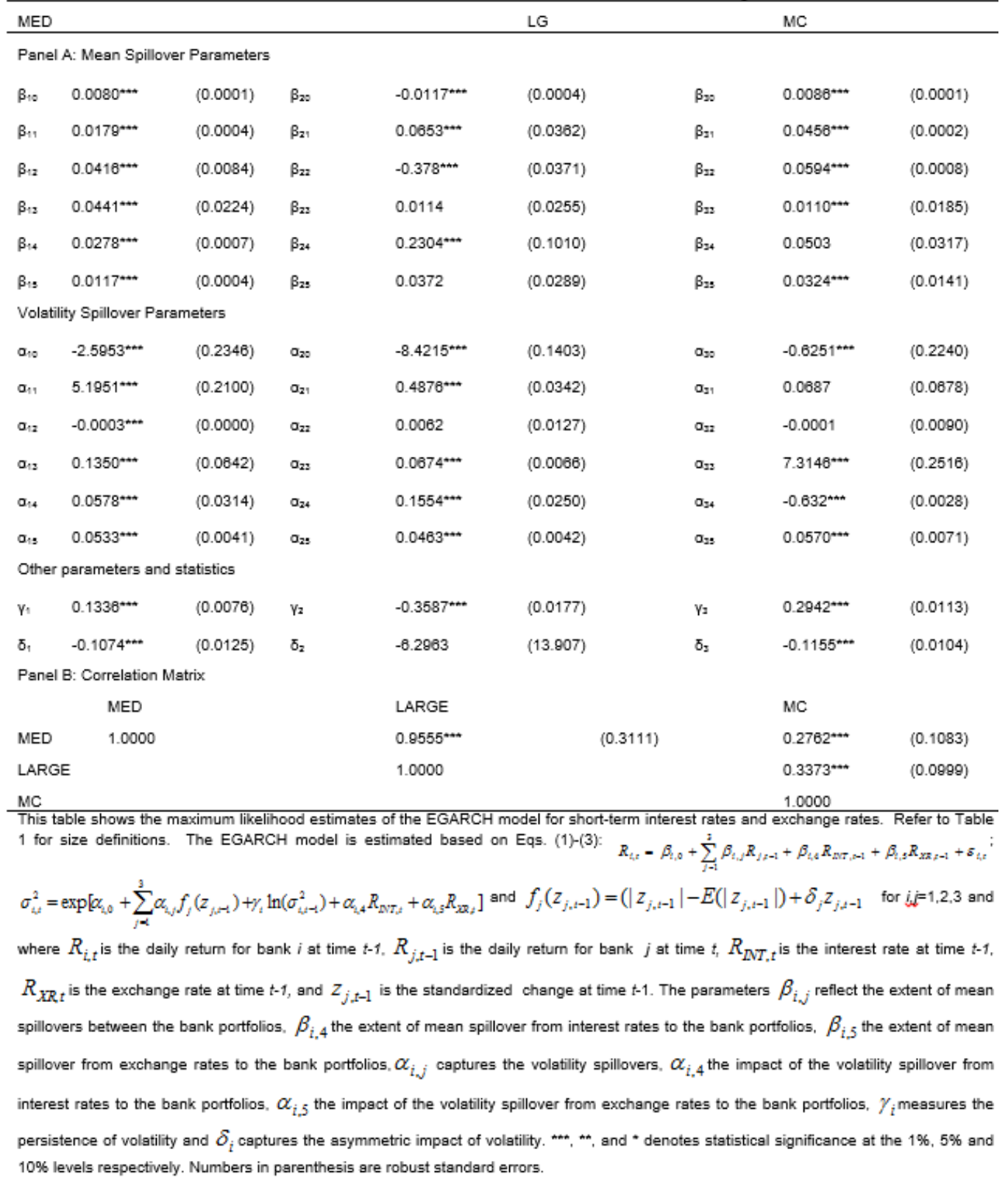

Table 2 also displays volatility spillovers. Volatility spillovers exist from shortterm interest rates and exchange rates to all the three MC, LG and MED banks. The signs of the volatility spillover coefficients for interest rates are negative and significant for MC banks whereas positive and significant for LG and MED banks. This indicates that when short-term interest rates are volatile then MC banks do not get a higher 
return whereas LG and MED banks get higher returns. This implies that changes in short-term interest rates impact the performance of large and medium banks more than the money center banks. The signs of exchange rate volatility spillover coefficients are all significant and positive. This indicates that higher the exchange rate volatility, the banks earn higher returns. Further, the demand for loans, loan commitments and supply of deposits are responsive to volatility of interest rates (Flannery, 1981). Further, banks are affected by exchange rate volatility due to the hedged and unhedged foreign exchange positions that the banks have.

Furthermore, in terms of volatility spillovers, MC banks spillover to the LG and MED banks, LG banks spillover to the MED banks and the MED banks spillover to the LG banks. This shows that the MC lead the LG and the MED banks. Also, we see a feedback effect from LG to the MED banks.

\section{Long-Term Interest Rates and Exchange Rates}

Table 3 displays the mean and volatility spillovers from long-term interest rates and exchange rates to the MC, LG and MED portfolios. Results indicate the presence of mean spillovers from interest rates and exchange rates to MC, LG, and MED banks. In terms of other mean spillovers, MC banks spillover to the LG and MED banks, LG spillover to the MC and MED banks and the MED banks spillover to the MC and LG banks. Additionally, there is a feedback effect from MC to LG and MED banks, LG to MC and MED banks and from MED to MC and LG banks.

Results further indicate volatility spillovers from interest rates and exchange rates to MC, LG, and MED banks. The signs of the volatility spillover coefficients for interest rates are negative and significant for all the banks. This indicates that neither of the banks gets higher returns when interest rates are more volatile. The coefficients for volatility spillover for exchange rates for MC banks is negative whereas positive and significant for the LG and MED banks. This is in contrast with the short-term interest rates and exchange rates where all the volatility spillover coefficients of exchange rates are positive. Further, in terms of other volatility spillovers, MC banks spillovers to LG and MED banks, LG banks spillover to MC and MED banks and the MED banks spillover to the MC and LG banks. Moreover, there is also a feedback effect from MC to $L G$ and MED banks, $L G$ to MC and MED banks and from MED to MC and LG banks. 
Table 3 -Maximum Likelihood Estimates of the EGARCH model for Long-term interest rates and Exchange rates

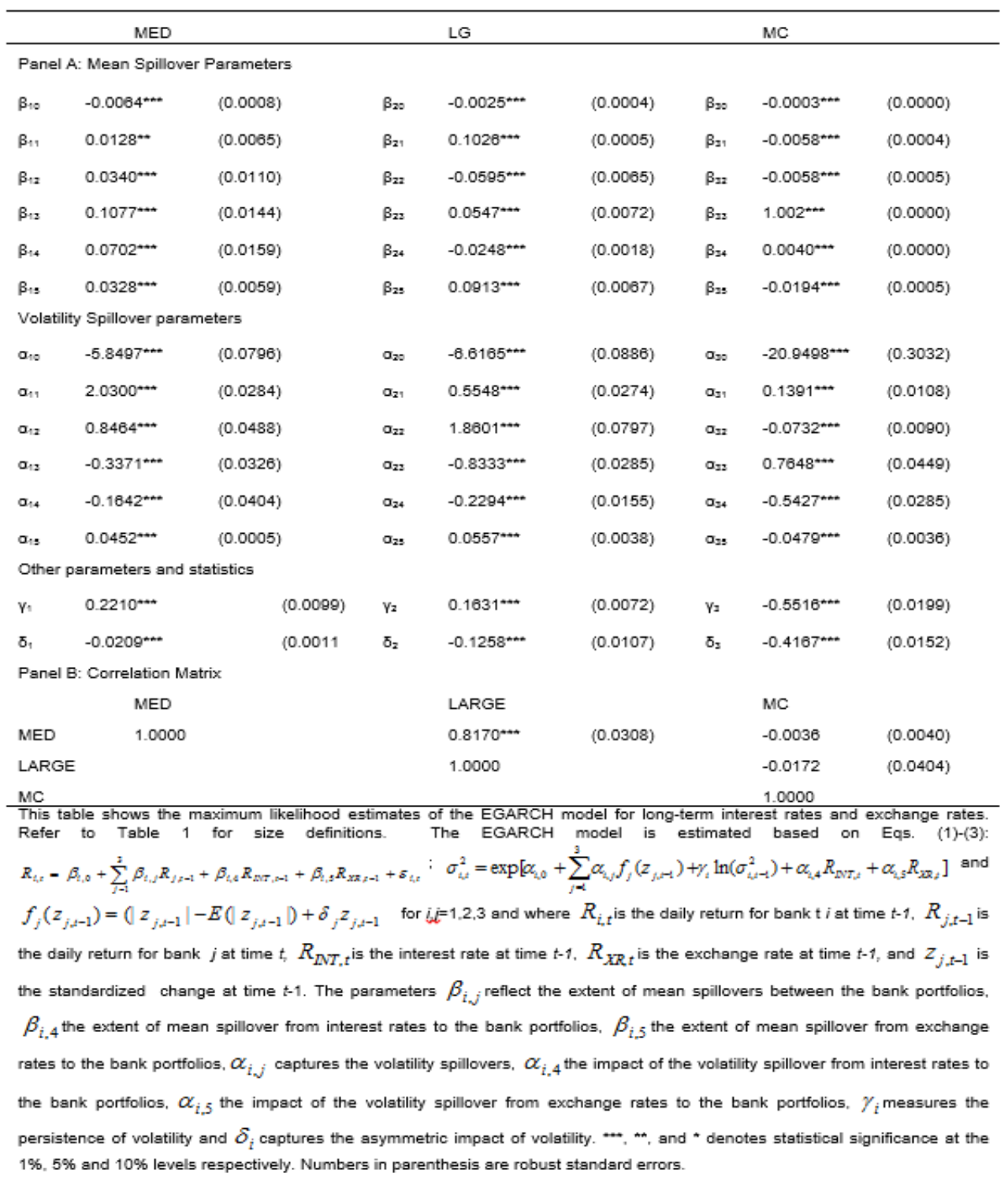

\section{Other Statistics for Short-Term Interest Rates, Long-Term Interest Rates and Exchange Rates}

Tables 2 and 3 show the cross-bank correlation coefficients between the volatilities of returns between the MC, LG and MED bank portfolios for short-term interest rates and exchange rates, and for long-term interest rates and exchanges rates respectively. These estimates are significant and suggest that the time-varying volatilities are correlated over time for all the three banks portfolios. 
Table 4 reports the residual based diagnostics tests developed by Engle and $\mathrm{Ng}$ (1993) to check whether the model is correctly specified. The asymmetry tests statistics - the sign bias, negative size, positive size, and joint tests show that there is no serial correlation in the standardized residuals. Thus I conclude that my model is correctly specified.

Table 4 - Residual Based Diagnostics Tests

\begin{tabular}{|c|c|c|c|}
\hline \multirow[t]{2}{*}{ Diagnostics check } & \multicolumn{3}{|c|}{$P$ values of statistics } \\
\hline & MED & LG & MC \\
\hline \multicolumn{4}{|l|}{ STI } \\
\hline Sign bias test & 0.0686 & 0.7345 & 0.2378 \\
\hline Negative size bias test & 0.0000 & 0.4210 & 0.2120 \\
\hline Positive size bias test & 0.0000 & 0.0255 & 0.3319 \\
\hline Join test & 0.0000 & 0.0311 & 0.4752 \\
\hline \multicolumn{4}{|l|}{ LTI } \\
\hline Sign bias test & 0.4194 & 0.8207 & 0.4357 \\
\hline Negative size bias test & 0.0010 & 0.0153 & 0.3280 \\
\hline Positive size bias test & 0.0002 & 0.0008 & 0.3741 \\
\hline Join test & 0.0001 & 0.0002 & 0.8104 \\
\hline \multirow{2}{*}{\multicolumn{4}{|c|}{$\begin{array}{l}\text { This table presents the results of the Engle and } \mathrm{Ng}(1993) \text { tests for } \\
\text { standardized residuals }\left(\varepsilon_{\mathrm{j}, \mathrm{t}} / \sigma_{\mathrm{j}, \mathrm{t}}\right)^{2} \text {. These tests as specified as follows } \\
\text { sign bias }\left(\mathrm{z}_{\mathrm{j}, \mathrm{t}}^{2} \equiv\left(\varepsilon_{\mathrm{j}, \mathrm{t}} / \sigma_{\mathrm{j}, \mathrm{t}}\right)^{2}=\alpha+\beta \mathrm{S}_{\mathrm{j}, \mathrm{t}}+\varepsilon_{j, t}\right)\end{array}$}} \\
\hline & & & \\
\hline \multicolumn{4}{|c|}{ negative size bias $\left(z_{j, t}^{2} \equiv\left(\varepsilon_{j, t} / \sigma_{j, t}\right)^{2}=\alpha+\beta S_{j, t} \varepsilon_{j, t-1}+e_{j, t}\right)$ : } \\
\hline \multicolumn{4}{|c|}{ positive sign bias $\left(z_{j, t}^{2} \equiv\left(\varepsilon_{j, t} / \sigma_{j, t}\right)^{2}=\alpha+\beta\left(1-S_{j, t}\right) \varepsilon_{j, t-1}+e_{j, t}\right)$ and } \\
\hline \multicolumn{4}{|c|}{ joint test $\left(z_{j, t}^{2} \equiv\left(\varepsilon_{j, t} / \sigma_{j, t}\right)^{2}=\alpha+\beta_{1} S_{j, t}+\beta_{2} S_{j, t} \varepsilon_{j, t-1}+\beta_{3}\left(1-S_{j, t}\right) \varepsilon_{j, t-1}+e_{j, t}\right)$} \\
\hline
\end{tabular}

\section{Volatility Persistence and Asymmetric Volatility Spillover Effects}

Table 5 reports the degree of volatility persistence as measured by $\delta_{j}$. The degree of volatility persistence is measured by half-life and is defined as $\ln (0.5) / \ln \left(\delta_{j}\right)$. The volatility shocks last on an average for 3.2 and 2.9 days for short-term interest rates and exchange rates and long-term interest rates and exchange rates respectively. 
Table 5 also shows the degree of asymmetric impact of negative and positive shocks. An asymmetric impact exists for MED, LG and MC banks. In case of shortterm interest rates and exchange rates, negative shocks increase volatility 1.2 times for MED banks, 0.7 times for LG banks and 1.2 times for MC banks. In case of long-term interest rates and exchange rates negative shocks increase volatility almost 1.2 times for MED and LG banks and 2.4 times for MC banks. Our results suggest that response asymmetries of positive and negative interest rate and exchange rate changes do exist on all the three bank stock returns. For all of these bank portfolios, negative shocks increase volatility more than the positive shocks. These banks are more sensitive to bad news than good news as a result of both short and long- interest rate and exchange rate changes.

Table 5 - Volatility Persistence and asymmetric volatility spillover effects

\begin{tabular}{|c|c|c|c|c|}
\hline & MED & LG & MC & Average \\
\hline \multicolumn{5}{|c|}{ Panel A: Degree of volatility persistence } \\
\hline STI & 5.1882 & 1.9324 & 2.3560 & 3.2 \\
\hline LTI & 3.1364 & 4.2498 & 1.2566 & 2.9 \\
\hline
\end{tabular}

Panel B: Degree of asymmetric impacts of negative and positive interest rate and exchange rate changes

$\begin{array}{llll}\text { STI } & 1.2406 & 0.7259 & 1.2612 \\ \text { LTI } & 1.0427 & 1.2878 & 2.4288\end{array}$

This table presents the degree of volatility persistence and the degree of asymmetric impacts of negative and positive changes. Panel A shows the degree of volatility persistence measured by halflife defined as $\ln (0.5) / \ln \left(\gamma_{i}\right)$. Panel B denotes the number of times negative changes increase volatility than positive changes. This is defined as $\left|-1+\delta_{i}\right| /\left(1+\delta_{i}\right)$. Refer to Table 1 for size definitions.

\section{Conclusions}

The goal of this paper of to examine the mean and volatility spillovers from short-term interest rates and exchange rates, and long-term interest rates and exchange rates, to bank portfolios of money center, medium and large banks. We also examine the response asymmetries of the changes in interest rates and exchanges rates on the bank portfolios. This issue is of importance to bankers, investors and policy makers as changes in banks stock returns due to changes in interest rates and exchange rates indicates banks' exposure to risk. Further, it is also important for bank regulators' to understand spillovers appropriately so that they can properly assess capital adequacy.

Results indicate mean and volatility spillovers from short-term interest rates and exchange rates, and long-term interest rates and exchange rates, to MC, LG and MED banks. In terms of mean and volatility spillovers from short-term interest rates and exchange rates. MC banks spillovers to MED banks, LG banks spillover to MED and MED banks spillover to LG banks. Additionally, there is a feedback effect from MC 
to MED and from LG to MED banks. For long-term interest rates and exchange rates, MC banks spillover to MED and LG, LG banks spillover to MED and MC banks and the MED abnsk spillover to the $L G$ and MC banks. There are also feedback effects seen from MC to LG and MED banks, LG to MC and MED bankd and from MED to MC and LG banks.

Results also show response asymmetries from short-term interest rates and exchange rates and long-term interest rates and exchange rates to all the three bank portfolios. These results show that MC, LG and MED banks are more sensitive to bad news than good news as a result of changes in short-term interest rates and exchange rates and long-term interest rates and exchange rates. These findings have important implications for bankers in terms of devising different hedging strategies against interest rates and exchange rate risks, for investors to determine their optimal choice of portfolio combinations and for banking regulators regarding their decisions about riskbased capital requirement.

\section{References}

Akella, S. R. and S. J. Chen. (1990). Interest rate sensitivity of bank stock returns: Specification effects and structural changes. Journal of Financial Research, 13, 147-154.

Bae, S. C. (1990). Interest rate changes and common stock returns of financial institutions: Revisited. Journal of Financial Research, 13, 71-79.

Bae, K.H. and G. A. Karolyi. (1994). Good news, bad news and international spillovers of stock return volatility between Japan and the U.S. Pacific-Basin Journal of Finance, 2, 405438.

Berndt, E. K., B. H. Hall, R. E. Hall, and J. A. Hausman. (1974). Estimation and inference in nonlinear structural models. Annals of Economics and Social Measurement, 3, 653-665.

Bollerslev, T.(1990). Modeling the coherence in short run nominal exchange rates: a multivariate generalized ARCH model. Review of Economics and Statistics, 72, 498-505.

Bollerslev, T., R., Y. Chou, and K. F. Kroner. (1992) ARCH modeling in finance: a review of theory and empirical evidence. Journal of Econometrics, 52, 5-59.

Bollerslev, T. and J. M. Woolridge. (1992). Quasi-Maximum Likelihood Estimation and inference in dynamic models with time-varying covariances. Econometric Review, 11, 143-172.

Booth, J. and D. T. Officer. (1985). Expectations, interest rates, and commercial bank stocks. Journal of Financial Research, 8, 51-58.

Chance, D. M. and W. R. Lane. (1980). A re-examination of interest rate sensitivity in the common stocks of financial institutions. Journal of Financial Research, 3, 49-55.

Cheung, Y. W. and L. K. Ng. (1992). Stock price dynamics and firm size: An empirical investigation. The Journal of Finance, 47, 1985-1997.

Choi, J. J., E. Elyasiani, and K. Kopecky. (1992). The sensitivity of bank stock returns to market, interest, and exchange rate risks. Journal of Banking and Finance, 16, 983-1004.

Choudhry T. (1994), Interdependence of stock markets: evidence from the Asian NIE's. Journal of Macroeconomics, 16, 629-680.

DeGoeij, P. and W. Marquering.(2002). Asymmetric volatility within and between stock and bond markets. Working paper, Leuvena and Erasmus University Rotterdam. 
Elyasiani, E. and I. Mansur. (1998). Sensitivity of Bank Stock Returns Distribution to Changes in the Level of Volatility of Interest Rate: A GARCH-M Model. Journal of Banking and Finance, 22, 535-563.

Elyasiani, E. and I. Mansur. (2004). Bank Stock Return Sensitivities to the Long-term and Short-term Interest Rates: A Multivariate GARCH Approach. Managerial Finance, 30, 32-55.

Engle, R. and K. F. Kroner. (1995). Multivariate Simultaneous Generalized ARCH. Economic Theory, 11, 122-150.

Engle, R. and V. K. Ng. (1993) Measuring and Testing the Impact of news on volatility. The Journal of Finance, 48, 1749-1778.

Engle, R., V. K. Ng, and M. Rothschild. 1990). Asset pricing with a factor ARCH covariance structure: Empirical estimates for Treasury Bills. Journal of Econometrics, 45, 213-238.

Eun, S. C. and S. Shim. (1989). The international transmission of stock markets movements. The Journal of Financial and Quantitative analysis, 24, 241-255.

Flannery, M. J. (1981). Market Interest Rates and Commercial Bank Profitability: An Empirical Investigation. The Journal of Finance, 36, 1085-1100.

Flannery, M. J. and C. M. James. (1984). The effect of interest rate changes on the common stock returns of financial institutions. The Journal of Finance, 39, 1141-1153.

Kane, E. J. and H. Unal. (1988). Change in market assessment of deposit institution riskiness. Journal of Financial Services Research, 2, 201-229.

Kasman, S., Vardar, G., Tunc, G. (2011). The impact of interest rate and exchange rate volatility on banks' stock returns and volatility: Evidence from Turkey. Economic Modelling, 28, 1328-1334.

Koutmos, G. (1992). Asymmetric volatility and risk return tradeoff in foreign stock markets. The Journal of Multinational Financial Management, 2, 27-43.

Koutmos, G., and G. G. Booth. (1995). Asymmetric volatility transmission in international stock markets. Journal of International Money and Finance, 14, 747-762.

Koutmos, G. (1996). Modeling the dynamic interdependence of major European stock markets. Journal of Business Finance and Accounting, 23, 975-88.

Kroner, K. E. and V. K. Ng. (1998). Modeling asymmetric comovements of asset returns. Review of Financial Studies, 1, 817-844.

Kwan, S. H. (1991). Reexamination of interest rate sensitivity of commercial bank stock returns using a random coefficient model. Journal of Financial Services Research, 5, 61-76.

Lynge, M. J. and J. K. Zumwalt. (1980). An empirical study of the interest rate sensitivity of commercial bank returns: A multi-index approach. Journal of Financial and Quantitative Analysis, 15, 731-742.

Lloyd, W. P. and R. A. Shick. (1977). A test of Stone's two-index model of returns. Journal of Financial and Quantitative Analysis, 12, 363-376.

Mansur, I. and E. Elyasiani. (1995). Sensitivity of Bank Equity Returns to the Level and Volatility of Interest Rates. Managerial Finance, 21, 58-77.

Nelson, D. (1991). Conditional heteroscedasticity in asset returns: A new approach. Econometrica, 59, 347-370.

$\mathrm{Ng}$, A. (2000). Volatility spillover effects from Japan and the US to the Pacific-basin. Journal of International Money and Finance, 19, 207-233.

Neuberger, J. A. (1993). Interest rate risk at US commercial banks. Federal Reserve Bank of San Francisco, Weekly Letters.

Saunders, A. and P. Yourougou. (1990). Are Banks Special? The Separation of Banking form Commerce and Interest Rate Risk. Journal of Economics and Business, 171-182. 
Scott, W. L. and R. L. Peterson. (1986). Interest rate risk and equity values of hedged and unhedged financial intermediaries. Journal of Financial Research, 9, 325-329.

So, R. (2001). Price and volatility spillovers between interest rate and exchange rate value of the U.S. dollar. Global Finance Journal, 12, 95-107.

Song, F. (1994). A two factor ARCH model for deposit-institution stock returns." Journal of Money, Credit and Banking, 26, 323-340.

Stone, B. K. (1974). Systematic interest rate risk in a two-index model of returns. Journal of Financial and Quantitative Analysis 9, 709-721.

Tai, C-S. (2000). Time-Varying Market, Interest Rate, and Exchange Rate Risk Premia in the US Commercial Bank Stock Returns. Journal of Multinational Financial Management, 10, 397-420.

Verma, P, Jackson, D. (2008). Interest rate and bank stock returns asymmetry: Evidence from U.S. banks. Journal of Economics and Finance, 32, 2, 105-118.

Wetmore, J. L. and J. R. Brick. (1994) Commercial bank risk: Market, interest rate, and Foreign exchange. Journal of Financial Research, 17, 585-596.

Yourougou, P. (1990). Interest Rate and the Pricing of Depository Financial Intermediary Common Stock: Empirical Evidence. Journal of Banking and Finance, 14, 803-820. 